\title{
Fluorescence quenching of 5-methyl-2-phenylindole (MPI) by carbon tetrachloride in different solvents and temperatures
}

\author{
Kalpana M Painagoni ${ }^{1}, \mathrm{H}_{\mathrm{D}}$ Patil $^{2}$ \\ ${ }^{1}$ Department of Physics, Government First Grade College, Gokak, Karntaka, India \\ ${ }^{2}$ Department of Physics, Basaveshwar Science College, Bagalkot, Karntaka, India
}

\begin{abstract}
The fluorescence quenching of 5-methyl-2-phenylindole (MPI) by carbon tetrachloride by steady state in different solvents, and by transient method in benzene has been carried out at room temperature. The Stern-Volmer (SV) plot has been found to be non-linear with a positive deviation for all the solvents studied. In order to interpret these results we have invoked the ground state complex and sphere of action static quenching models. Using these models various rate parameters have been determined. The magnitudes of these parameters imply that sphere of action static quenching model agrees well with the experimental results. Hence the positive deviation in the SV plots is attributed to the static and dynamic quenching. Further, from the studies of temperature dependence of rate parameters and lifetime measurements, it could be explained that the positive deviation is due to the presence of a small static quenching component in the overall dynamic quenching. With the use of finite sink approximation model, it was possible to check whether these bimolecular reactions as diffusion limited and to estimate independently distance parameter $R^{\prime}$ and mutual diffusion coefficient $D$. Finally an effort has been made to correlate the values of $R^{\prime}$ and $D$ with the values of the encounter distance $R$ and the mutual diffusion coefficient $D$ determined using the Edward's empirical relation and Stokes-Einstein relation.
\end{abstract}

Keywords: Fluorescence quenching; MPI; Solvent effect; Finite sink approximation model; Sphere of action static quenching model

\section{Introduction}

Fluorescence quenching of aromatic hydrocarbons in solvents by various quenchers like aniline, bromobenzene, carbon tetra chloride $\left(\mathrm{CCl}_{4}\right)$, ethyltrithiocarbonate, halide ions, metal ions, etc. has been a subject of continued investigation for the last couple of decades [1-11]. The study has been mainly to understand the nature of biomolecular reactions taking place both under study state and transient conditions. This study has not only been of importance in physical sciences but also in chemical, biological and medical sciences[1218].The fluorescence yield in bimolecular liquid systems is hindered due to several mechanisms such as static and dynamic quenching, excimer and exciplex formation, charge transfer processes, etc. One of the well-known experimental techniques used to study the role of fluorescence quenching is to determine the quenching rate parameter using Stern-Volmer (SV) plots. If the quenching mechanism is mainly due to dynamic process, then it will be largely due to diffusion in which case diffusion rate parameter $\mathrm{k}_{\mathrm{d}}$ equals the quenching rate parameter $\mathrm{kq} \quad\left(=\mathrm{K}_{\mathrm{sv}} / \tau_{\mathrm{o}}\right)$ where $\mathrm{K}_{\mathrm{sv}}$ is the slope of the linear plot and t0 is the decay time of the solute in the absence of the quencher. On the other hand, if the experimental results do not simulate with the simple linear SV equation, then it may be due to one of the above processes other than or along with diffusion processes. In the present study we have used both steady-state and transient experimental setup to investigate the quenching of 5-methyl2-phenylindole (MPI)by $\mathrm{CCl}_{4}$ in four different organic solvents with a view to understand the nature of quenching mechanism involved in these systems. MPI is widely used as a Laser dye and has several applications such as anticoagulants fluorescence indicator and optical brightness properties [14]. The various rate parameters responsible for fluorescence quenching have been determined by sphere of action static quenching model. In the light of these rate parameters, lifetime measurements and dependence of quenching rate parameter on the temperature of the medium, the possible quenching mechanisms are discussed.

\section{Theory}

The dynamic process in which quenching mechanism is mainly due to collision is governed by the linear SV equation

$$
\begin{aligned}
& \mathrm{I}_{\mathrm{o}} / \mathrm{I}=1+\mathrm{K}_{\mathrm{sv}}[\mathrm{Q}], \\
& \tau_{\mathrm{o}} / \tau=1+\mathrm{K}_{\mathrm{sv}}[\mathrm{Q}],
\end{aligned}
$$

where $I_{0}$ and $\tau_{0}$ are the fluorescence intensity and fluorescence lifetime in the absence of quencher, $I$ and $\tau$ are the fluorescence intensity and fluorescence lifetime in the presence of quencher $[Q], \mathrm{K}_{\mathrm{sv}}\left(=\mathrm{k}_{\mathrm{q}} \tau_{\mathrm{o}}\right)$ and $\mathrm{K}_{\mathrm{sv}}^{\prime}\left(=\mathrm{k}_{\mathrm{q}}^{\prime}\right.$ 
$\left.\tau_{\mathrm{o}}\right)$ are SV constant and $\mathrm{k}_{\mathrm{q}}\left(=\mathrm{k}_{\mathrm{q}}\right.$ ') is the quenching rate parameter. Eqs. (1) and (2) are applicable as long as the experimental results show linear variation. The departure from linearity in SV plot, suggests that quenching mechanism is not purely collisional and this may be attributed either to the ground state complex formation or to the sphere of action static quenching model [7].

In order to see whether the ground state complex formation is partly playing a role, one can use extended SV equation $[19,20]$ given by

$$
\left[\left(\mathrm{I}_{\mathrm{o}} / \mathrm{I}\right)-1\right] /[\mathrm{Q}]=\left(\mathrm{K}_{\mathrm{sv}}+\mathrm{k}_{\mathrm{g}}\right)+\left(\mathrm{K}_{\mathrm{sv}} \mathrm{k}_{\mathrm{g}}\right)[\mathrm{Q}]
$$

where $\mathrm{K}_{\mathrm{sv}}$ is the $\mathrm{SV}$ constant and $\mathrm{k}_{\mathrm{g}}$ is the ground state association constant. From Eq. (3), the values of $\mathrm{K}_{\mathrm{sv}}$ and $\mathrm{k}_{\mathrm{g}}$ can easily be determined by least-squares fit method.

The ground state complex formation takes place if quenching constant $\mathrm{k}_{\mathrm{q}}\left(=\mathrm{K}_{\mathrm{sv}} / \tau_{\mathrm{o}}\right)$ obtained from Eq. (3) agrees well with that obtained from the lower portions of the plot according to Eq. (1). In that case static quenching is very low. Apart from this, the ground state complex formation may be noticed if there is a change in the absorption and fluorescence spectra even at higher concentrations of quencher.

In order to see whether static quenching process is playing a role, one can use "sphere of action static quenching model', According to this model, the instantaneous or static quenching occurs if the quencher molecule is very near to, or in contact with the fluorescent molecule at the exact moment it happens to be excited. This was explained by the fact that only a certain fraction ' $\mathrm{W}$ ' of the excited state is actually quenched by the collisional mechanism. Some molecules in the excited state, the fraction of which is (1-W), are deactivated almost instantaneously after being formed, because a quencher molecule happens to be randomly positioned in the proximity at the time the molecules are excited and interacts very strongly with them. Several models were employed (Smoluchowski model) [21, 22] to describe this static quenching process, all leading to the following modified form of the SV equation.

$$
\left(\mathrm{I}_{\mathrm{o}} / \mathrm{I}\right)=1+\mathrm{K}_{\mathrm{sv}}[\mathrm{Q}] / \mathrm{W}
$$

As W depends on the quencher concentration [Q], the SV plots for a quencher with a high quenching ability generally deviate from linearity. Thus it is worth rewriting Eq. (4) as

$$
\left[1-\left(\mathrm{I}_{\mathrm{o}} / \mathrm{I}\right)\right] /[\mathrm{Q}]=\left(\mathrm{K}_{\mathrm{sv}}\left(\mathrm{I}_{\mathrm{o}} / \mathrm{I}\right)+(1-\mathrm{W}) /[\mathrm{Q}]\right.
$$

From Eq. (5) one can easily calculate $K_{\text {sv }}$ and the values of $\mathrm{W}$ by least-squares fit method. According to Zeng et al. [20] and Andre et al. [24], if the distance between the quencher molecule and the excited molecule lies between the encounter distance and the kinetic distance, the static effect takes place especially in the case of steady-state experiments irrespective of ground state complex formation provided reactions are limited by diffusion.

\section{Experimental details}

he solute MPI was a generous gift from a colleague from Department of Chemistry, Gulbarga University, Gulbarga and is of scintillation grade. The molecular structure of MPI is shown in Fig. 1. The quencher $\mathrm{CCl}_{4}$ was obtained from BDH laboratory, UK and was of HPLC grade. All other solvents were obtained from s-d fine chemicals Ltd., India. They were of spectroscopic grade and used without any further purification. The solutions were prepared keeping the concentration of MPI fixed $\left(1 \times 10^{-4} \mathrm{M}\right)$ and varying the quencher concentration $(0.02-0.10 \mathrm{M})$ in all the solvents. Fluorescence spectrophotometer F-2000 (Hitachi Japan make Bandwidth $10 \mathrm{~nm}$ ) was used for fluorescence intensity measurements, with perpendicular geometry. Fluorescence measurements were made taking fresh solution each time in a rectangular quartz cell having an airtight stopper. The solute has maximum absorption at $280 \mathrm{~nm}$. The solute was excited at $280 \mathrm{~nm}$ and the fluorescence spectrum was recorded. The maximum fluorescence corresponds to $332 \mathrm{~nm}$. First the fluorescence intensity $\mathrm{I}_{\mathrm{o}}$ was measured without the quencher and then the fluorescence intensity I was measured at different quencher concentrations and at a fixed solute concentration. Measurement of fluorescence lifetime of the solute with and without quencher, and at different temperatures was made by single photon counting time-domain spectrometer (Edinburgh Instrument, UK, Model EI-199). Hydrogen gas was used to fill the Lamp of the single photon counting (SPC) system at 0.6 atm pressure, keeping electrode separation $0.7 \mathrm{~mm}$, applying the discharge voltage of about $7 \mathrm{kV}$ and operating the Lamp at a frequency of $30 \mathrm{kHz}$, with this setting, Lamp pulses having pulse width of about $1 \mathrm{~ns}$ at FWHM were obtained. A nonlinear least-squares iterative reconvolution mathematical procedure was used here. The fluorescence lifetime data were analyzed by considering reduced chi-square $\left(\chi_{r}^{2}\right)$ value. The observed fluorescence decays were monoexponential. It has been found that the value of $\left(\chi_{r}^{2}\right)$ is nearly equal to 1 . The experimental values are reproducible within $5 \%$ of the experimental error. Description of the experimental setup is discussed elsewhere [13]. 


\section{Tables and Figures}

\subsection{Tables}

Table 1.The values of Stern-Volmer constant $K_{\mathrm{sv}}$, bimolecular quenching rate parameter $k_{q}$, static quenching constant $V$ and kinetic distance $r$ for different solvents.

\begin{tabular}{|l|l|l|l|l|}
\hline Solvent & Ksv $\left(\mathrm{M}^{-1}\right)$ & $\begin{array}{l}\mathbf{k}_{\mathrm{q}} \mathbf{X} 10 \mathrm{X}^{-10} \\
\left(\mathrm{M}^{-1} \mathrm{~s}^{-1}\right)\end{array}$ & $\begin{array}{l}\mathbf{V} \\
\left(\mathrm{mol}^{-1} \mathrm{dm}^{3}\right)\end{array}$ & $\mathbf{r}(\AA)$ \\
\hline Toluene & 78.78 & 10.00 & 22.34 & 20.69 \\
\hline Benzene & 19.51 & 2.49 & 2.73 & 9.80 \\
\hline Cyclohexane & 22.80 & 2.91 & 58.09 & 28.40 \\
\hline DMSO & 15.90 & 2.03 & 14.78 & 18.00 \\
\hline
\end{tabular}

$$
R_{Y}=3.98 \AA, R_{Q}=2.73 \AA, \tau_{0}=0.784 \mathrm{~ns} \text {. }
$$

Table 2. The values of $K_{s v}^{0}$ (steady-state quenching constant at $[Q]=0$ ), mutual diffusion coefficient $D$, distance parameter $\mathbf{R}^{\prime}, 4 \pi N^{\prime} D R^{\prime}$, quenching rate parameter $\mathbf{k}_{\mathbf{q}}$, coefficient of viscosity $\boldsymbol{\eta}$ and solvent polarity $\varepsilon$

\begin{tabular}{|c|c|c|c|c|c|c|c|}
\hline Solvent & $\begin{array}{l}K_{s v}^{0} \\
\left(\mathbf{d m}^{3} \mathbf{m o l}^{-1}\right)\end{array}$ & $\begin{array}{c}\mathbf{D} \times 10^{5} \\
\left(\mathrm{~cm}^{2} \mathbf{s}^{-1}\right)\end{array}$ & $\begin{array}{c}\mathbf{R}^{\prime} \\
(\AA)\end{array}$ & $\begin{array}{c}4 \pi N^{\prime} D R^{\prime} \times 10^{-10} \\
\left(\mathbf{M}^{-1} \mathbf{s}^{-1}\right)\end{array}$ & $\mathbf{k q} \times 10^{-10}\left(\mathbf{M}^{-1} \mathbf{s}^{-1}\right)$ & $\begin{array}{c}\mathbf{\eta}(\mathbf{m} \\
\text { pasec })\end{array}$ & $\varepsilon$ \\
\hline Toluene & $\mathbf{5 3 . 1 0}$ & $\mathbf{7 . 5 0}$ & $\mathbf{1 1 . 9 3}$ & $\mathbf{6 . 7 7}$ & $\mathbf{1 0}$ & $\mathbf{0 . 5 9}$ & $\mathbf{2 . 3 8}$ \\
\hline Benzene & $\mathbf{0 . 1 4 6}$ & $\mathbf{3 6 . 6 0}$ & $\mathbf{0 . 6 8}$ & $\mathbf{0 . 0 1 2}$ & $\mathbf{2 . 4 9}$ & $\mathbf{0 . 6 5}$ & $\mathbf{2 . 2 8}$ \\
\hline Cyclohexane & $\mathbf{1 9 . 3 5}$ & $\mathbf{2 . 5 0}$ & $\mathbf{1 3 . 0 4}$ & $\mathbf{2 . 4 7}$ & $\mathbf{2 . 9 1}$ & $\mathbf{0 . 9 8}$ & $\mathbf{2 . 0 2}$ \\
\hline DMSO & $\mathbf{8 . 3 2}$ & $\mathbf{2 . 1 9}$ & $\mathbf{6 . 4 0}$ & $\mathbf{1 . 0 6}$ & $\mathbf{2 . 0 3}$ & $\mathbf{2 . 2 0}$ & $\mathbf{4 . 7 0}$ \\
\hline
\end{tabular}

$$
\mathbf{R}\left(=\mathbf{R}_{\mathbf{Y}}+\mathbf{R}_{\mathbf{Q}}\right)=6.71 \AA \dot{\AA} .
$$

Table 3. The values of mutual diffusion coefficients $D^{a}$ and $D^{b}$, distance parameter $R^{\prime}$ and encounter distance $\mathbf{R}$

\begin{tabular}{|c|c|c|c|}
\hline Solvent & $\mathbf{D}^{\mathrm{a}} \times \mathbf{1 0}^{\mathbf{5}}\left(\mathrm{cm}^{2} \mathrm{~s}^{-1}\right)$ & $\mathbf{D}^{\mathrm{b}} \times 10^{5}\left(\mathrm{~cm}^{2} \mathrm{~s}^{-1}\right)$ & $\mathbf{R} \AA$ \\
\hline Toluene & 3.91 & 7.50 & 11.93 \\
\hline Benzene & 2.39 & 36.60 & $\mathbf{0 . 6 7 5}$ \\
\hline Cyclohexane & 2.20 & 2.50 & 13.04 \\
\hline DMSO & 0.98 & 2.19 & 6.40 \\
\hline
\end{tabular}

$$
\mathbf{R}\left(=\mathbf{R}_{\mathbf{Y}}+\mathbf{R}_{\mathbf{Q}}\right)=6.71 \AA ̊ .
$$

${ }^{a}$ Diffusion coefficients determined from Stoke-Einstein relation.

${ }^{b}$ Diffusion coefficients determined from finite sink approximation model.

Table 4. The values of intercept, range of $W$, static quenching constant $V$ and radii of the sphere of action (kinetic distance) $r$ for $\left(\mathrm{MPI}+\mathrm{CCl}_{4}\right)$ system at different temperatures

\begin{tabular}{|c|c|c|c|c|}
\hline Temperature $\left({ }^{\circ} \mathrm{C}\right)$ & Intercept & Range of W & $\mathrm{V}\left(\mathrm{mol}^{-1} \mathrm{dm}^{3}\right)$ & $\mathbf{r}(\AA)$ \\
\hline 30 & 4.44 & $0.56-0.91$ & 5.86 & 13.2 \\
\hline 40 & 6.66 & $0.33-0.87$ & 10.90 & 16.2 \\
\hline 50 & 1.89 & $0.81-0.96$ & 2.09 & 9.39 \\
\hline 60 & 3.79 & $0.62-0.92$ & 4.76 & 12.3 \\
\hline
\end{tabular}

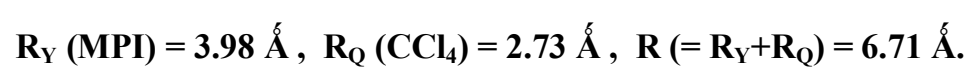

Table 5. The Stern-Volmer quenching constant $K_{\mathrm{sv}}$, the quenching rate parameter $k_{\mathrm{q}}$ at different temperatures and the activation energy $\mathrm{E}_{\mathrm{q}}$ for collisional quenching process for $\left(\mathrm{MPI}+\mathrm{CCl}_{4}\right)$ system.

\begin{tabular}{|c|l|l|l|}
\hline Temperature $\left({ }^{0} \mathrm{C}\right)$ & $\mathbf{K}_{\mathrm{sv}}\left(\mathbf{M}^{-1}\right)$ & $\mathbf{k}_{\mathrm{q}} \mathbf{x 1 0 ^ { - 9 }}\left(\mathrm{M}^{-1} \mathbf{s}^{-1}\right)$ & $\mathbf{E}_{\mathrm{q}}\left(\mathrm{kJmol}^{-1}\right)$ \\
\hline 30 & 5.57 & 6.61 & 20.29 \\
\hline 40 & 6.66 & 7.90 & \\
\hline 50 & 9.73 & 11.54 & \\
\hline 60 & 11.12 & 13.19 & \\
\hline
\end{tabular}




\subsection{Figures}<smiles>Cc1ccc2[nH]c(-c3ccccc3)cc2c1</smiles>

Fig. 1. Molecular structure of MPI

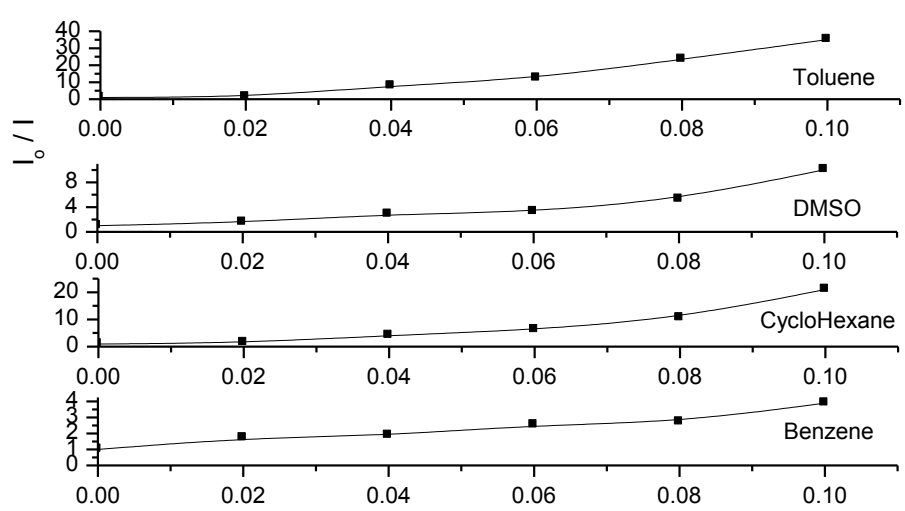

[Q]

Fig. 2. Stern-Volmer plots of $I / I 0$ against $[Q]$ in different solvents.

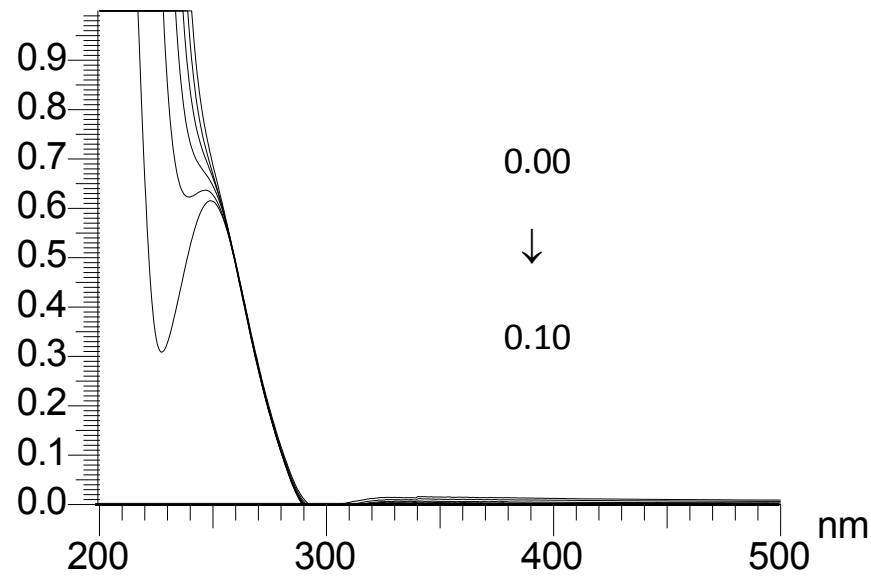

Fig. 3 Absorption spectra of MPI $\left(C=1 \times 10^{-4} \mathrm{M}\right)$ in the presence of $\mathrm{CCl}_{4}$ in hexane at $27^{\circ} \mathrm{C}$. Concentrations of $\mathrm{CCl}_{4}(0.00,0.02,0.04,0.06,0.08$ and to $0.10 \mathrm{M})$

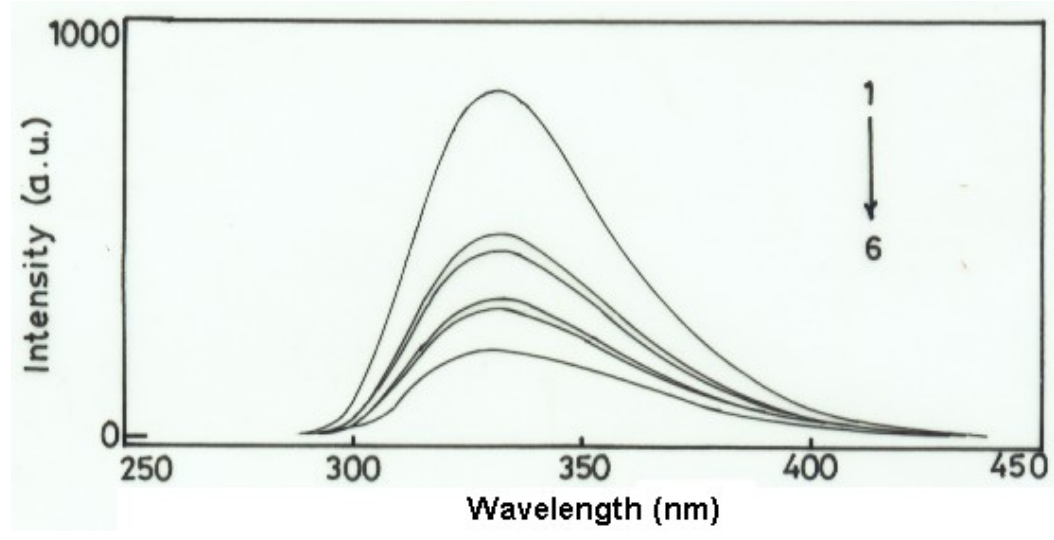


Fig. 4. Fluorescence emission spectra of $\mathrm{MPI}\left(\mathrm{C}=1 \times 10^{-4} \mathrm{M}, \lambda_{\mathrm{ex}}=280 \mathrm{~nm}\right)$ in presence of $\mathrm{CCl}_{4}$ in benzene at $27^{\circ} \mathrm{C}$. Concentrations of $\mathrm{CCl}_{4}(0.00,0.02,0.04,0.06,0.08$ and to $0.10 \mathrm{M})$

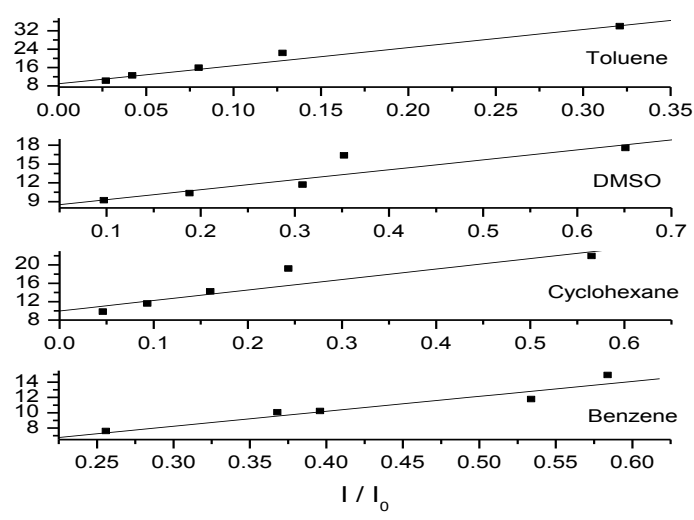

Fig. 5. Plots of $\left[1-\left(I / I_{0}\right)\right] /[Q]$ against $\mathbf{I} / \mathbf{I}_{0}$ for $M P I+\mathbf{C C l}_{4}$ system in different solvents.

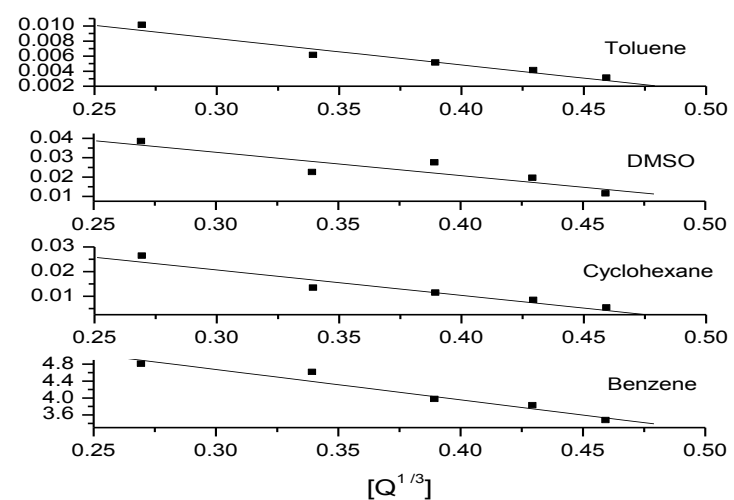

Fig. 6. Plots of $\mathrm{K}^{-1}{ }_{\mathrm{sv}}$ versus $[\mathrm{Q}]^{1 / 3}$ in different solvents.
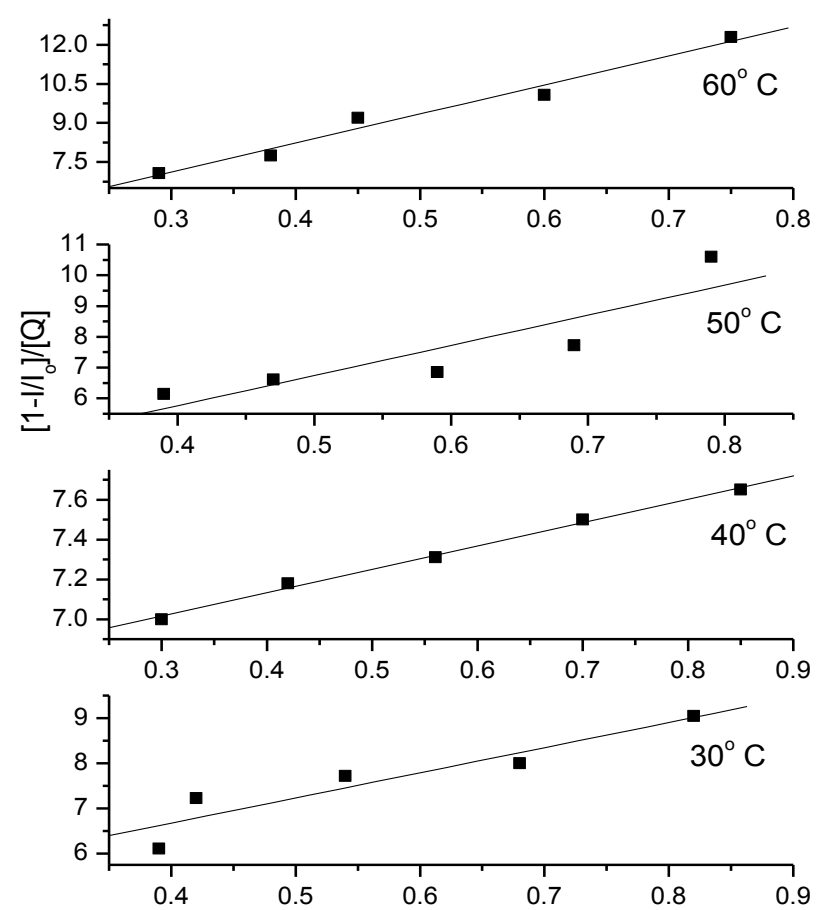

Fig. 7 Plots of $\left[1-\left(\mathrm{I} / \mathrm{I}_{0}\right)\right] /[\mathrm{LQ}]$ against $\mathrm{I} / \mathrm{I}_{\mathbf{0}}$ for $\mathrm{MPI}+\mathrm{CCl}_{4}$ system in benzene at different temperatures. 


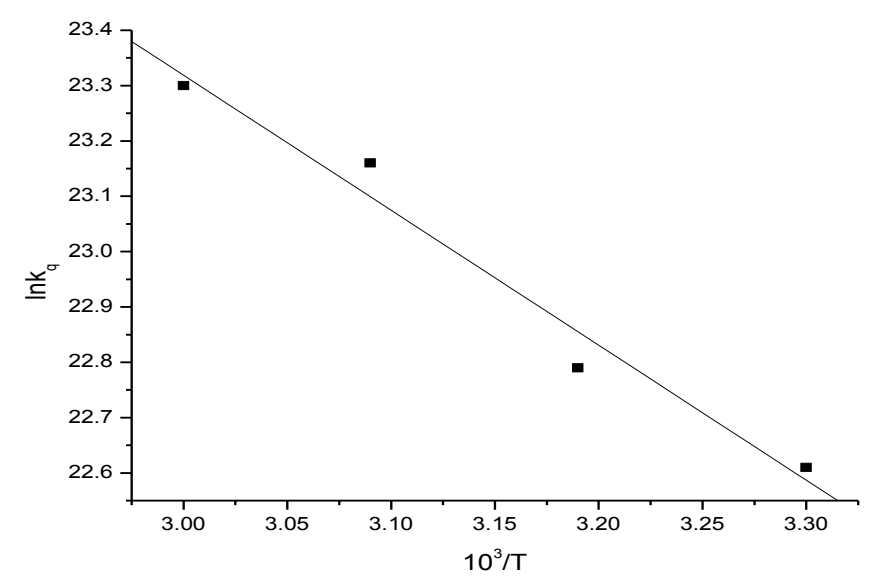

Fig 8. Plot of $\ln k_{q}$ versus $10^{3} / T$ for MPI $+\mathrm{CCl}_{4}$ system.

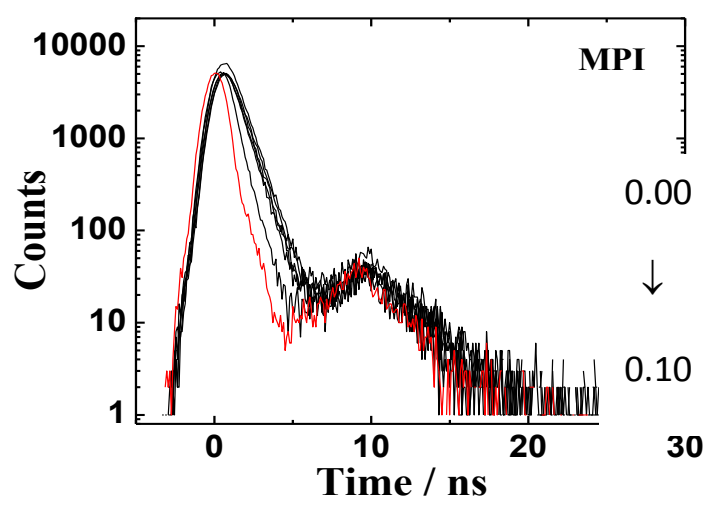

Fig. 9 Fluorescence decay profiles of MPI at different quencher concentrations of $\mathrm{CCl}_{4}(0.00,0.02,0.04,0.06,0.08$ and $0.10 \mathrm{M})$.

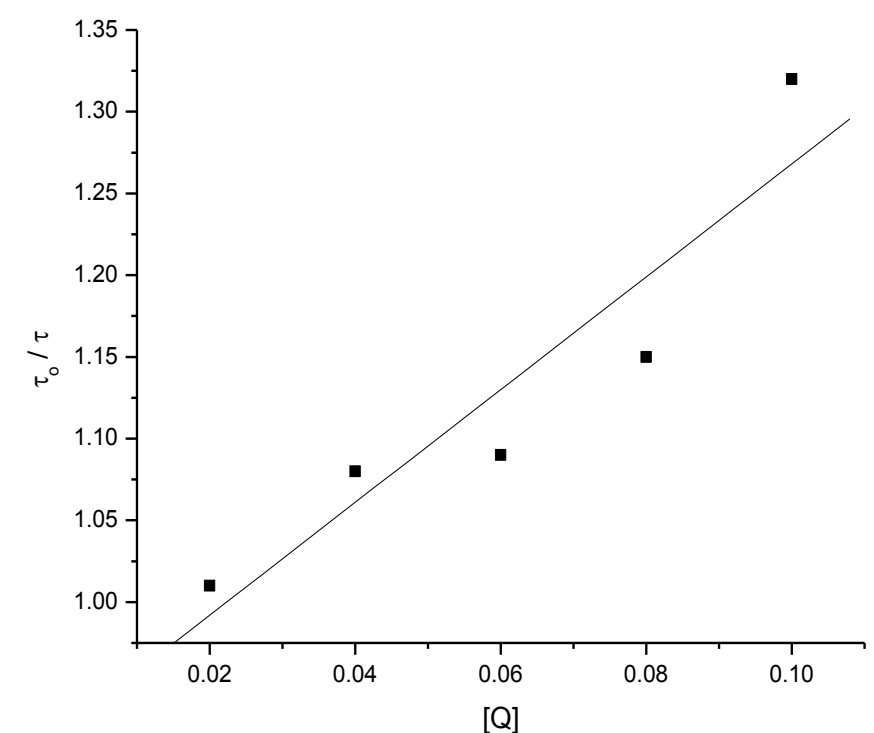

Fig. 10. Stern-Volmer plot of $\tau_{0} / \tau$ versus $[Q]$ in benzene for $\mathrm{MPI}+\mathrm{CCl}_{4}$ system 


\section{Results and discussion}

The SV plots obtained by using the experimentally determined values of $I_{o}$ and I are found to be nonlinear in all the solvents showing positive deviation and are shown in Fig. 2. Similar experimental results were also observed by others [1-6]. Thus, positive deviation from linearity suggests that quenching is not purely collisional and this may be attributed either to the ground state complex formation or to the sphere of action static quenching model [7].

The values of $\mathrm{K}_{\mathrm{sv}}$ from Eq. (3) were found to be imaginary in all the solvents. Therefore, the role of ground state complex formation is ruled out in the present case. This is also confirmed by the fact that there is no shift in the peak position in the absorption spectrum of MPI in hexane, and emission spectrum of MPI in benzene at different quencher concentrations as shown in Figs. 3 and 4. These facts show that Eq. (3) is not applicable for the analysis of the data corresponding to the observed positive deviation in the SV plots. Thus the analysis of the data for positive deviation in the SV plot was made using "sphere of action static quenching model"'. Fig. 5 shows the plots of $\left[1-\left(\mathrm{I} / \mathrm{I}_{0}\right)\right] /[\mathrm{Q}]$ against $\mathrm{I} / \mathrm{I}_{\mathrm{o}}$ for MPI with $\mathrm{CCl}_{4}$ as quencher in different solvents which are linear according to Eq. (5).

The dynamic quenching constant $\mathrm{K}_{\mathrm{sv}}$ is determined in all the cases by least-squares fit method using Eq. (5) and the values are given in Table 1. Fluorescence lifetime $\tau_{0}$ is given at the bottom of Table 1. Bimolecular quenching rate parameter $\mathrm{k}_{\mathrm{q}}$ was determined from the experimentally determined values of $\mathrm{K}_{\mathrm{sv}}$ and $\tau_{\mathrm{o}}$ according to the relation $\mathrm{k}_{\mathrm{q}}=\mathrm{K}_{\mathrm{sv}} / \tau_{\mathrm{o}}$ and the values are given in Table 1. In order to support static and dynamic effects, we have determined the magnitudes of static quenching constant $\mathrm{V}$ and radii $\mathrm{r}$ of sphere of action (or kinetic distance) using the abovementioned theory for sphere of action model. By using equations $\mathrm{W}=\mathrm{e}^{-\mathrm{V}[\mathrm{Q}]}, \mathrm{V} / \mathrm{N}_{\mathrm{o}}=$ $\left(4 \pi r^{3}\right) / 3$ and (5) the values of $\mathrm{V}$ and $\mathrm{r}$ are determined by least-squares fit method in all the solvents and are given in Table 1. Similar results were also obtained by others $[7,12,29]$. The radii of the solute $\left(\mathrm{R}_{\mathrm{Y}}\right)$ and the quencher $\left(\mathrm{R}_{\mathrm{Q}}\right)$ molecules were determined by adding the atomic volumes of all the atoms constituting the molecule as suggested by Edward [23] and are given at the bottom of Table 1. From these values of $R_{Y}$ and $R_{Q}$, the sum of the molecular radii $[\mathrm{R}]$ of the solute MPI and the quencher $\mathrm{CCl}_{4}$ is determined. This sum of the molecular radii $\mathrm{R}$ is referred to as encounter distance or contact distance or reactive distance. This value of $\mathrm{R}$ is then compared with the values of ' $r$ ' to verify whether the reaction is due to sphere of action model. From Table 1 we see that the values of kinetic distance ' $r$ ' are greater than the encounter distance $R$. Therefore, according to Zeng et al. [20] and Andre et al. [24] the static effect takes place irrespective of ground state complex formation provided reactions are limited by diffusion indicating that the sphere of action model holds well in our case also. Further it may also be noted that a positive deviation in SV plot is expected when both static and dynamic quenching occurs simultaneously [19].

Further to find out whether the reactions are diffusion limited we invoke the finite sink approximation model [25-27] for steady state which helps us to estimate independently the mutual diffusion coefficient D, distance parameter R' and activation energy-controlled rate constant $\mathrm{k}_{\mathrm{a}}$. The modified SV equation [20].

$$
\begin{aligned}
& k_{s v}^{-1}=\left(k_{s v}^{0}\right)^{-1}-\frac{\left(2 \pi N^{\prime}\right)^{1 / 3}}{4 \pi N^{\prime} D \tau_{0}}[Q]^{1 / 3} \\
& K_{s v}^{0}=\frac{4 \pi N^{\prime} D R \tau_{o} k_{a}}{4 \pi N^{\prime} D R+k_{a}}
\end{aligned}
$$

Finite sink approximation model is used to determine the values of $\mathrm{D}, \mathrm{R}_{\mathrm{o}}$ and $\mathrm{k}_{\mathrm{a}}$. For efficient quenching processes the value of $K_{s v}$ is often observed to increase with [Q] [20]. Hence the values of $K_{s v}$ were determined at each quencher concentration in all the solvents and the values of $k_{s v}^{-1}$ are also determined. Fig. 6 shows the plots of $k_{s v}^{-1}$ against $[\mathrm{Q}]^{1 / 3}$. From these figures we see that all the plots in different solvents are almost linear and small deviation may be due to experimental uncertainties. Hence, the linear dependence of $k_{s v}^{-1}$ on the one-third power of quencher concentration within the error limits is confirmed [20]. Then the least-squares fit value of $K_{s v}^{0}(\mathrm{SV}$ constant at $[\mathrm{Q}]=0)$ was obtained from the intercept of the plot of $k_{s v}^{-1}$ against $[\mathrm{Q}]^{1 / 3}$, according to Eq. (6). Similarly, mutual diffusion coefficients D were determined from the slope of the Eq. (6) by least-squares fit method and the values of $K_{s v}^{0}$ and D are given in Table 2. Using these values of $K_{s v}^{0}$ and D, the distance parameter $\mathrm{R}_{\mathrm{o}}$ was determined according to equation $\mathrm{K}_{\mathrm{sv}}=4 \pi N^{\prime} D R^{\prime} \tau_{o}$ and the values are given in Table 2. According to Joshi et al. [28] the bimolecular reactions are said to be diffusion limited if the values of $\mathrm{k}_{\mathrm{q}}$ (determined from Eq. (5)) are greater than $4 \pi N^{\prime} D R^{\prime}$. Hence the values of $4 \pi N^{\prime} D R^{\prime}$ are calculated using the experimentally determined values of $R_{0}$ and $D$ of Eq. (6) and are given in Table 2 . We see from the table that 
in all the solvents the values of $\mathrm{k}_{\mathrm{q}}$ are greater than $4 \pi N^{\prime} D R^{\prime}$, which is an expected result for diffusion-limited reaction [27]. When we compare the quenching rate parameter $k_{\mathrm{q}}$ with solvent polarity and viscosity, it is found that $\mathrm{k}_{\mathrm{q}}$ is independent of solvent polarity but depends on solvent viscosity. This fact is clear from Table 2 . While $\mathrm{k}_{\mathrm{q}}$ is high in toluene, the less viscous solvent, it is low in DMSO, the most viscous solvent. Hence no correlation exists between $\mathrm{k}_{\mathrm{q}}$ and solvent polarity.

It is important to note that, when an attempt was made to correlate the experimentally determined values of mutual diffusion coefficient $\mathrm{D}$ and distance parameter R' using finite sink approximation model with the corresponding values of $\mathrm{D}$ and $\mathrm{R}$ calculated from Stoke-Einstein relation and Edward's empirical relations respectively in all the systems, the values of D and R' (or R) determined from the two methods are quite comparable. From Table 3 it is clear that correlation fails in some other solvents. Similar discrepancies have also been observed by others $[20,28]$ in some bimolecular quenching reactions. This may be due to the uncertainties in the values of adjustable parameter ' $a$ ' in the Stoke's-Einstein relation and the approximation in the values of atomic volume in the Edward's relation. Hence we may conclude that finite sink approximation model is valid in recovering the parameters D and R'(or R). In order to check whether these reactions are diffusion limited, the temperature dependence of rate constant $\mathrm{k}_{\mathrm{q}}$ is examined. The fluorescence quenching was carried out in the temperature range $30-60^{\circ} \mathrm{C}$ by both steady state and transient methods. Fluorescence lifetime $\tau_{\mathrm{o}}$ of MPI at different temperatures is measured by single photon counting time-domain spectrometer (Edinburgh Instrument, UK, Model EI-199). No variation in fluorescence lifetime with temperature was observed. This may be due to the following fact. The molecular structure of MPI may be such that the gap between S1 and T2 may be narrow or may lie on the same line or such that even state order gets inverted on heating, i.e. T2 lies below S1. When this happens, there is no increase in the rate of non-radiative intersystem crossing. Hence the lifetime of MPI remain almost constant over the temperature range of our study [30]. Therefore, we have used the average value of $\tau_{\text {av }}(=0.844 \mathrm{~ns})$ at all temperatures. The SV plots at all temperatures show positive deviation. By using Eq. (5), the plot of $\left[1-\left(\mathrm{I} / \mathrm{I}_{\mathrm{o}}\right)\right] /[\mathrm{Q}]$ against $\mathrm{I} / \mathrm{I}_{\mathrm{o}}$ was plotted at all temperatures and shown in Fig. 7. From linear fit values, $\mathrm{K}_{\mathrm{sv}}$ and $\mathrm{V}$ are determined and are listed in Table 4 . The values of quenching rate $\mathrm{k}_{\mathrm{q}}$ was calculated at all temperatures and listed in Table 5. From this table it is clear that $\mathrm{K}_{\mathrm{sv}}$ increases with temperature since $\mathrm{k}_{\text {diff }}$ increases, as expected. $\mathrm{K}_{\mathrm{sv}}$ depends on temperature through the temperature dependence of rate constant $\mathrm{k}_{\mathrm{q}}$ and the fluorescence lifetime $\tau(\mathrm{t})$. It has been assumed that $\mathrm{k}_{\mathrm{q}}$ is proportional to exp (-Eq/RT) [1]. Where $\mathrm{E}_{\mathrm{q}}$ is the activation energy for collisional process, $R$ the gas constant and $T$ the absolute temperature. Thus the value of $E_{q}$ can be determined on the slope of the plot lnkq versus inverse of the absolute temperature T. Fig. 8 shows the plot of $\operatorname{lnkq}$ versus $10^{3} / \mathrm{T}$ for $\mathrm{MPI}+\mathrm{CCl}_{4}$ system. From this figure it can be seen that the plot is linear. From the least-squares fit value of the slope of this plot, the value of $\mathrm{E}_{\mathrm{q}}$ has been determined and is given in Table 5 . Similar values of $E_{q}$ have been obtained by others also [1-4]. The values of $E_{q}$ being approximately equal to the values obtained by others suggest that the rates of reactions are limited by diffusion of the reactants through the solvents. These facts suggest the presence of static quenching component in overall dynamic quenching. The fluorescence decay profile for MPI $+\mathrm{CCl}_{4}$ in benzene at different quencher concentrations is shown in Fig. 9. Further, we checked whether a transient effect also play a role in the overall dynamic quenching process. If transient effect is playing a role, the plot of $\left(\tau_{0} / \tau\right)$ against $[Q]$ is not linear. But from Fig. 10, it is observed that the plot of $\left(\tau_{0} / \tau\right)$ against $[Q]$ is linear. It indicates that transient effect is not playing a role in quenching process. This fact is also supported by the variation of static quenching constant with temperature. Thus the linearity of $\left(\tau_{\mathrm{o}} / \tau\right)$ with $[\mathrm{Q}]$ and the variation of $\mathrm{V}$ prompt us to suggest that positive deviation in the SV plot in the system is due to the presence of static quenching component in overall dynamic quenching.

\section{Conclusion}

From the above discussion we observe that: (1) the SV plots show positive deviation leading to high values of $\mathrm{k}_{\mathrm{q}}$, indicating efficient fluorescence quenching. (2) Static quenching constant ' $\mathrm{V}$ ' and kinetic distance ' $\mathrm{r}$ ' are in agreement with the corresponding literature values. (3) The value of $\mathrm{k}_{\mathrm{q}}$ is greater than $4 \pi N ' D R$ ' in all solvents. (4) Further, the values of R' and D determined from the finite sink approximation model are close to the values determined from Edward's and Stokes-Einstein empirical relations, respectively. In view of the above facts we may conclude that quenching reaction is diffusion limited and both static and dynamic quenching processes are partly playing a role in this system.

\section{References}

[1] R. Roy, S. Mukherjee, Chem. Phys. Lett. 140 (1987) 210.

[2] J. Tipperudrappa, D.S. Biradar, M.T. Lagare, S.M. Hangodimath, S.R. Inamdar, J.S. Kadadevarmath, J. Photochem. Photobiol. A: Chem. 177 (2006) 89.

[3] D. Goswami, R.S. Sarpal, S.K. Dogra, Bull. Chem. Soc. Japan 64 (1991) 3137.

[4] S.M. Hangodimath, G.S. Gadginmath, G.C. Chikkur, Appl. Radiat. Isot. 41 (1990) 817.

[5] A. Rani, S.J. Sobhanadri, T.A. Prasad Rao, J. Photochem. Photobiol. 33 (1996) 749.

[6] P.K. Behra, T. Mukhergee, A.K. Mishra, J. Lumin. 65 (1995) 131. 
[8] M. Swaminathan, N. Radha, Spectrochim. Acta Part A 60 (2004) 1839.

[9] C. Hariharan, A.K. Mishra, Radiat. Meas. 32 (2) (2000) 113.

[10] H.M. Suresh Kumar, R.S. Kunabenchi, J.S. Biradar, N.N. Math, J.S. Kadadevaramath, S.R. Inamdar, J. Lumin. 116 (2006) 35.

[11] S. Nigam, S.K. Dogra, Ind. J. Chem. 32A (1993) 290

[12] S.M. Hanagodimath, G.C. Chikkur, G.S. Gadaginmath, Chem. Phys. 148 (2,3) (1990) 347.

[13] J.S. Kadadevaramath, T.P. Giraddi, G.C. Chikkur, Radiat. Meas. (USA) 26 (1) (1996) 17.

[14] P. Cyril, S.A. Maged, J.J. Aaron, B. Michada, T. Alphonse, C. Lamine, Spectrosc. Lett. 27 (4) (1994) 439.

[15] S.M. Hanagodimath, G.C. Chikkur, G.S. Gadaginmath, Acta Phys. Pol. A 81 (3) (1992) 361.

[16] S.M. Hanagodimath, G.C. Chikkur, G.S. Gadaginmath, Pramana J. Phys. (India) 37 (2) (1991) 153.

[17] E.A. Lissi, M.V. Encians, S.G. Birtolotti, J.J. Cosa, C.M. Previtali, Photochem. Photobiol. 51 (1990) 53

[18] S. Nigam, M. Belletete, R.S. Sarpal, G. Durocher, J. Chem. Soc. Faraday Trans. 91 (1995) 2133.

[19] P.K. Behera, A.K. Mishra, J. Photochem. Photobiol. A: Chem. 71 (1993) 115.

[20] H. Zeng, G. Durocher, J. Lumin. 63 (1995) 75.

[21] J.M. Frank, S.J. Wawilow, Z. Phys. 69 (1931) 100.

[22] A.Y. Moon, D.C. Poland, H.A. Scheraga, J. Phys. Chem. 69 (1965) 2960.

[23] J.T. Edward, Chem. Ind. (London) (1956) 774.

[24] J.C. Andre, M. Niclause, W.R. Ware, Chem. Phys. 28 (1978) 371

[25] J. Keizer, J. Phy. Chem. 86 (1982) 5052.

[26] J. Keizer, J. Am. Chem. Soc. 107 (1985) 5319.

[27] J. Keizer, Chem. Rev. 87 (1987) 167.

[28] G.C. Joshi, R. Bhatnagar, S. Doraiswamy, N. Periasamy, J. Phys. Chem. 94 (1990) 2908

[29] J.B. Birks, M. Salete, S.C.P. Leite, Proc. Phys Soc. (London) 3 (1970) 417.

[30] S. Kumar, G. Giri, S.C. Mishra, M.K. Machwe, Indian J. Pure Appl. Phys. 33 (1995) 615. 